REVISTA DE LITERATURA E CULTURA RUSSA

\title{
Três leitores de Dostoiévski: Kulidjánov, Bresson e Scorsese
}

\author{
Three readers of Dostoevsky: \\ Kulidjanov, Bresson and Scorsese
}

Autor: Paulo Roberto Mendonça Lucas

Universidade Federal Fluminense, Niterói, Rio de Janeiro, Brasil

Edição: RUS Vol. 12. N 20

Publicação: Dezembro de 2021 DOI: https://doi.org/10.11606/issn.2317-4765.rus.2021..189137 


\section{Três leitores de Dostoiévski: Kulidjánov, Bresson e Scorsese ${ }^{1}$}

\section{Paulo Roberto Mendonça Lucas*}

Resumo: Este ensaio apresenta uma leitura de três obras cinematográficas que, de diferentes formas, levaram às telas a ficção de Fiódor Dostoiévski. Os filmes Crime e castigo (1971), de Liev Kulidjánov, $O$ batedor de carteiras (1959), de Robert Bresson, e Taxi Driver (1976), de Martin Scorsese, são analisados e relacionados às narrativas de Crime e castigo e Memórias do subsolo. Dessa maneira, o texto objetiva explicitar a estreita relação que a sétima arte manteve/mantém com a literatura de Dostoiévski.
Abstract: This essay presents a reading of three cinematographic works that, in different ways, brought Fyodor Dostoevsky's fiction to the screen. The films Crime and Punishment (1971), by Liev Kulidjánov, The Pickpocket (1959), by Robert Bresson, and Taxi Driver (1976), by Martin Scorsese, are analyzed and linked to the narratives of Crime and Punishment and Memories from the Underground. In this way, the text aims to explain the close connection that the seventh art maintained/maintains with Dostoevsky's literature.

Palavras-chave: Dostoiévski; Kulidjánov; Bresson; Scorsese; Adaptação; Cinema Keywords: Dostoevsky; Kulidjanov; Bresson; Scorsese; Adaptation; Cinema 
"Dostoiévski é o maior cineasta do mundo"

Luiz Fernando Carvalho
* Doutor e mestre em Estudos de Literatura pela Universidade Federal Fluminense; graduado em Letras (Port. / Francês / Literaturas) pela mesma instituição. Professor de Língua Francesa do Ensino Básico; http://lattes.cnpq. br/5908919535761547; https:// orcid.org/0000-0002-9061-2443; paulomendonca@id.uff.br

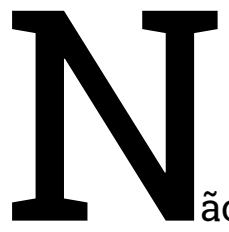

ão são poucos os filmes que objetivam transpor às telas de cinema obras escritas por Fiódor Dostoiévski, sobretudo seus romances mais conhecidos. Neste ensaio, tomaremos como ponto de partida uma das adaptações mais literais de Crime e castigo: a obra homônima de Lev Kulidjánov, que é uma referência incontornável quando tratamos de adaptações/leituras cinematográficas dos romances de Dostoiévski. Em seguida, veremos de que maneira a obra dostoievskiana se faz presente em filmes como $O$ batedor de carteiras e Taxi driver, que, à primeira vista, não pretendem ser adaptações propriamente ditas, mas leituras que se valem de narrativas preexistentes como inspiração na elaboração do roteiro e, por conseguinte, da história que pretendem contar.

O termo adaptação, apesar de seu desgaste, ${ }^{2}$ talvez seja o mais adequado para nos referirmos a uma obra que teve por objetivo narrar, na forma de um filme, aquilo que se pensou inicialmente como literatura. Ao falarmos em adaptação, sabemos que, por questões óbvias relativas à estrutura de uma película, teremos perdas e ganhos em comparação ao texto de que esta se origina. Uma adaptação estritamente literal seria algo quase irrealizável, embora não completamente impossível. Para torná-la exequível, precisaríamos transpor às telas, palavra por palavra, o texto original. Se não é possível fazê-lo - e, muitas vezes, nem desejável, já que "a questão da fidelidade não é interessante em si mesma"3 -, é perfeitamente compreensível que um diretor opte por realizar uma adap-

1 Em parte, este artigo é fruto da Tese: "A literatura em cena: Woody Allen leitor de Dostoiévski", defendida sob orientação do Prof. Dr. André Dias, no Programa de Pós-Graduação em Estudos de Literatura do Instituto de Letras da Universidade Federal Fluminense - UFF, Niterói, Rio de Janeiro.

2 MITERRAND, 2014, p. 15

3 MITERRAND, 2014, p. 31 
tação que, dentro dos limites e possibilidades da linguagem cinematográfica, se atenha ao máximo ao texto original, que funciona, portanto, como uma espécie de "norte" a guiar todos os elementos que estarão presentes em cena ou que, tecnicamente, servirão para compô-la: iluminação, enquadramento, cenografia, figurino, fotografia, trilha sonora, tomadas em diferentes planos, atores e, claro, diálogos e/ou monólogos.

Poder-se-ia pensar que a adaptação "fiel" de uma obra literária é, exatamente por sua pretensa fidelidade, facilmente realizável. Afinal, o autor da obra-fonte já fez grande parte do trabalho. É claro que essa é uma visão bastante ingênua, pois desconsidera as inúmeras dificuldades que roteiristas e diretores de um filme experimentam quando da adaptação de uma história que pode funcionar muito bem como romance, mas que, se não for corretamente estruturada, não funcionará em sua versão cinematográfica. Por vezes, a escrita de Dostoiévski em Crime e castigo parece pouco convidativa a qualquer especialista que pretenda adaptá-la. Se, por um lado, os diálogos em abundância podem ser um alento para quem conduz a adaptação, por outro, a presença marcante de monólogos interiores (para citar apenas um exemplo) dificulta sobremaneira a vida de quem precisará descobrir uma forma de envolver o espectador na narrativa sem torná-la "monótona". É necessário reconstruir a atmosfera sombria e angustiante que se produz quando lemos, sossegadamente, os devaneios e pensamentos de Raskólnikov, mas cinema e literatura são manifestações artísticas que possuem tempos distintos; o tempo que sobra em uma falta em outra. Nesse caso específico, a dificuldade se dá porque, muitas vezes, Raskólnikov fala demasiadamente à sua consciência (característica comum a inúmeras personagens dostoievskianas), o que está distante, a priori, do alcance da câmera.

Um aspecto fundamental do filme de Lev Kulidjánov é sua opção pela filmagem monocromática. Apenas essa escolha já nos introduz em uma atmosfera parecida com aquela que encontramos na obra de Dostoiévski. Com efeito, a narrativa de Crime e castigo não é, sob qualquer ponto de vista, dotada de matizes coloridos. Aliás, o próprio herói (ou anti-herói) do 
romance é uma personagem sombria: "A opção pelo preto e branco permite traduzir as zonas de sombra da alma e a perturbação pela culpa que atormentam Raskólnikov". ${ }^{4} \mathrm{O}$ filme de Kulidjánov busca reproduzir essa característica marcante da personagem desde o princípio, tomando a liberdade de iniciar-se com um pesadelo em que o jovem estudante foge literalmente da polícia pelas ruas de São Petersburgo até, por fim, lançar-se de uma ponte. Nesse momento, Raskólnikov acorda em estado de grande confusão. Começamos a "ler" seus pensamentos, que continuam nas cenas seguintes, enquanto ele passeia, atormentado, pela cidade e, ainda, enquanto observa a rua e as pessoas através da janela de seu "cubículo". Durante essa sequência inicial, Kulidjánov praticamente reproduz o texto de Dostoiévski, e o faz, a meu ver, com razão. Trata-se de um momento de suma importância do romance, em que entramos em contato, pela primeira vez, com as ideias e questionamentos de Raskólnikov a respeito do crime que pretende cometer. Convém relembrar suas palavras: "O que é mesmo que estou indo fazer? Será que tenho capacidade para aquilo? Será que aquilo é sério? Sério coisa nenhuma. Então é para alimentar a fantasia que me distraio: brincadeira! É, vai ver que é brincadeira mesmo". ${ }^{5}$

Um dos maiores méritos da adaptação empreendida por Kulidjánov é sua capacidade de adaptar fielmente o texto de Dostoiévski, sem que essa fidelidade resulte em uma obra destituída da dinâmica narrativa particular que é necessária a uma obra cinematográfica. De modo geral, esse "respeito" ao romance que verificamos desde as primeiras cenas se repetirá ao longo de todo o filme. Nesse sentido, devem nos importar, fundamentalmente, as soluções encontradas pelo diretor a fim de dar conta de situações que se resolvem com alguma "facilidade" em um romance, mas que, eventualmente, podem se apresentar complexas no cinema. A questão da atmosfera da obra, como vimos, foi compreendida por Kulidjánov, que optou por realizar um filme em preto e branco. Já quando Raskólni-

4 CARLOS, 2013, p. 44

5 DOSTOIÉVSKI, 2009a, p. 20 - grifos do autor 
kov confabula consigo mesmo acerca do crime que planeja, nas cenas iniciais, o diretor russo mantém-se fiel ao texto de Dostoiévski e se vale de um recurso específico do cinema que não encontra par, por questões óbvias, na literatura: a trilha sonora. Enquanto Raskólnikov reflete sobre a possibilidade de um assassinato, ouvimos ao fundo o som de um realejo, cuja melodia alegre contrasta diametralmente com o aspecto sombrio do jovem estudante de Direito. Eis um dos caminhos traçados por Kulidjánov para destacar o caráter contraditório da personalidade de seu herói. Além da música, a fotografia do filme, ao explorar os contrastes do preto e branco, também serve ao mesmo fim. São aspectos como esses que devem nos interessar quando tratamos de uma adaptação que pretende seguir à risca o texto a que se filia.

Embora o filme de Kulidjánov consiga alcançar um grau muito elevado de fidelidade em relação ao romance de Dostoiévski, há pequenas liberdades tomadas pelo diretor que não passam despercebidas pelo espectador mais atento que já conheça, através do romance, a história de Raskólnikov. Na verdade, diferentemente do que ocorre com outras leituras de Crime e castigo, nessa adaptação não há qualquer acréscimo ao texto original, mas algumas ausências significativas que não podem ser atribuídas à "falta de tempo" característica do cinema. Ao menos não nesse caso, uma vez que o filme em questão tem duração de quase quatro horas, o que significa dizer que $o$ diretor tinha a intenção sincera de realizar uma adaptação das mais fiéis possíveis. Além da ausência da cena marcante em que Sônia lê a Raskólnikov o trecho do evangelho que trata da ressurreição de Lázaro (possivelmente devido à censura exercida pelo governo soviético), a maneira como romance e filme se encerram também merece nota.

Na obra de Dostoiévski, há um fim para além da última página, pois a presença do epílogo estende a obra para um momento posterior à confissão de culpa de Raskólnikov. É através dessa "continuação" que, em alguma medida, o romance se encerra de maneira "positiva", ao explicar o que aconteceu com Raskólnikov. Ademais, o epílogo deixa claro que a vida do jovem mudou completamente a partir do crime cometido. 
Seu arrependimento sincero ensejou o nascimento de outro homem, cuja história também poderia ser contada em um romance. Em suma, parece claro que Dostoiévski aposta na redenção, ao passo que não a encontramos na adaptação de Kulidjánov. Ora, as cenas derradeiras do filme são de Raskólnikov, que, diante de Iliá Pietróvitch, confessa, ainda que hesitante, ter assassinado a velha usurária e sua irmã com golpes de machado. Aqui, não é plausível supor, como no caso da cena ausente na qual o evangelho é personagem central, que se trata de uma restrição devido à censura imposta pelo regime soviético. Nesse caso específico, podemos acreditar na escolha do diretor, que preferiu, conscientemente, "concluir" a vida de Raskólnikov no momento de sua confissão. Se há redenção, ela é apenas sugerida ao espectador, mas de modo algum explicada em detalhes (quase pedagogicamente), como $o$ faz Dostoiévski. Isso demonstra, de maneira clara, que mesmo em uma adaptação que se pretenda fiel à obra original é possível encontrar as marcas do diretor, roteirista e todos aqueles que de alguma forma contribuíram para sua realização.

Finalmente, devemos lembrar que, no filme de Kulidjánov, os planos fixos concentram toda a atenção naquilo que, segundo Bakhtin, ${ }^{6}$ é uma das características fundamentais do romance dostoievskiano: o diálogo, isto é, o confronto de ideias entre as personagens. Em Crime e castigo, assim como em todas as obras polifônicas de Dostoiévski, os diálogos se sobrepujam significativamente às ações propriamente ditas. É como se estas fossem apenas um "pretexto" para aquilo que verdadeiramente interessa e que será apresentado através da interação verbal entre as personagens. Por essa razão, a opção do diretor se alinha àquilo que o romance, o texto original, parece transmitir ao leitor. Como percebe Cássio Starling Carlos em comentário sobre o filme, a própria escolha do formato em que este seria rodado contribui para amplificar os sentidos da obra: "o formato CinemaScope, além de distinguir a produção com signo da grandiosidade da tela de cinema, amplifica a im-

6 BAKHTIN, 2013. 
pressão de isolamento do personagem". ${ }^{7} \mathrm{O}$ isolamento de que fala o crítico é, de fato, uma das particularidades marcantes da personalidade de Raskólnikov. Ao optar por um formato que, em alguma ou grande medida, contribui para intensificar tal característica, uma vez mais Kulidjánov demonstra que sua adaptação objetiva respeitar ao máximo as prováveis intenções que tivera Dostoiévski quando concebeu sua personagem mais conhecida.

O filme de Kulidjánov veio à luz na União Soviética em 1970, isto é, mais de um século após a publicação do romance de Dostoiévski. Contudo, antes dessa data, já se realizara uma das mais bem-sucedidas leituras cinematográficas de Crime e castigo. Esse status, até hoje, não parece ameaçado. Refiro-me ao filme $O$ batedor de carteiras (Pickpocket, 1959), de Robert Bresson, diretor cuja obra, segundo Jean-Luc Godard, é síntese do cinema francês: "He is the French cinema, as Dostoievsky is the Russian novel and Mozart is German music". ${ }^{8} \mathrm{O}$ filme de Bresson nos apresenta a história de Michel, um jovem que não enxerga qualquer perspectiva de futuro, mas que possui talento incomum para o crime, especialmente para o furto de carteiras e relógios nos metrôs e estações de trens de Paris. Mesmo que os crimes de Michel não sejam, juridicamente, tão graves quanto os de Raskólnikov, boa parte dos principais questionamentos discutidos no romance de Dostoiévski estão presentes em $O$ batedor de carteiras; mais que isso, as próprias personagens principais se assemelham àquelas que encontramos em Crime e castigo. Há, pois, uma espécie de "espelhamento" no que diz respeito ao núcleo central de personagens a partir das quais a narrativa se desenvolve: Michel / Raskólnikov; Jacques / Razumikhin; Jeanne / Sônia; Porfiri Pietróvitch / Inspetor principal.

É interessante notar como a estrutura de um dos filmes mais conhecidos de Bresson toma emprestada muitas características comuns à literatura. Antes dos créditos iniciais, o especta-

7 CARLOS, 2013, p. 44

8 Ele é o cinema francês, como Dostoiévski é o romance russo e Mozart a música alemã. (tradução nossa) - GODARD, 1972, p. 47. 
dor se depara com uma espécie de prólogo no qual se explica, em linhas gerais, o estilo e os objetivos do autor quando da criação da história a que assistiremos na sequência:

“Ce film n'est pas du style policier. L'auteur s'efforce d'exprimer, par des images et des sons, le cauchemar d'un jeune homme poussé par sa faiblesse dans une aventure de vol à la tire pour laquelle il n'était pas fait". 9

Não apenas o conteúdo deste "prólogo" nos chama atenção; sua própria existência, independentemente da mensagem que veicula, já demonstra a opção do diretor por um cinema em que a palavra e, por conseguinte, o texto possuem grande valor: "o cinematógrafo é uma escrita com imagens em movimento e sons". ${ }^{10}$ Sob certa perspectiva, o texto que introduz o filme de Bresson pode ser comparado, guardadas algumas diferenças pontuais, à nota de apresentação assinada por Dostoiévski em Memórias do subsolo. Nela, encontramos uma declaração explícita de que o que leremos a seguir, embora seja ficção, pode perfeitamente servir como representação de uma realidade comum à época. Aqui, não há qualquer intenção de negar o caráter ficcional da obra; ao contrário, este é afirmado pelo próprio autor.

No filme do diretor francês, o simples fato de nos depararmos com a mensagem de que "este não é um filme de estilo policial" nos condiciona, desde o início, a entender que o que veremos não é a realidade, mas uma representação; um filme que não pode ser enquadrado dentro de um estilo específico. Nesse ponto, convém destacar outra semelhança entre Bresson e Dostoiévski. A despeito de possuir diversos elementos que futuramente estariam presentes nos chamados romances policiais, Crime e castigo não pertence a esse gênero. $O$ crime é menos importante que suas consequências, e o culpado é conhecido pelo leitor desde as primeiras páginas. Em $O$ batedor de carteiras, anuncia-se, deliberadamente, algo semelhante. Afirmar que não se trata de um filme policial significa,

9 Este filme não é do estilo policial. 0 autor se esforça por exprimir, através de imagens e sons, o pesadelo de um jovem impulsionado por sua fraqueza a uma aventura de roubo para a qual não foi feito. (tradução nossa) - O BATEDOR..., 1959, cap. 1.

10 BRESSON, 2014, p. 19 
assim como no romance de Dostoiévski, que a identidade do criminoso não é questão fundamental. A vida e as angústias desse jovem, subtende-se, são os elementos que verdadeiramente terão valor para a narrativa. Além disso, de certo modo, há nessa lacônica introdução uma espécie de julgamento do diretor em relação à sua personagem, que, qual Raskólnikov, não é um criminoso par excellence, mas foi "impulsionado por sua fraqueza" em direção a um mundo ao qual não pertence.

A maneira como a narrativa de $O$ batedor de carteiras se apresenta ao espectador reforça a ideia de que o cinema de Bresson possui uma forte influência da literatura. No filme, Michel é o narrador responsável por escrever, literalmente, a própria história. A importância das palavras se traduz não apenas através do voiceover, mas, sobretudo, por meio das tomadas em primeiro e primeiríssimo planos das folhas em que a personagem registra, a posteriori, os acontecimentos de sua vida. Aqui, a palavra escrita também é protagonista. Ademais, a narrativa em primeira pessoa, a desesperança na vida e a relação fria que Michel mantém com a mãe nos conduzem a outra conhecida personagem literária, desta sorte da literatura francesa. É difícil não associar as características de Michel às de Mersault, narrador-protagonista de um dos mais célebres romances de Albert Camus: $O$ estrangeiro. Podemos enxergar Michel, portanto, como espécie de simbiose das personagens de Dostoiévski e Camus; amálgama que une, em um só sujeito, as frustrações, dúvidas, melancolia, desesperança e ambições (ou a falta delas) que conformam as personalidades de Raskólnikov e Mersault.

Apesar de Crime e castigo e $O$ batedor de carteiras contarem histórias, aparentemente, distintas (já que o furto de carteiras não poderia ser comparável ao assassinato), Bresson faz uma leitura que, na medida do possível, preserva algumas cenas importantes do romance de Dostoiévski. Uma delas é a "confissão" do inspetor geral no quarto de Michel. Como em Crime e castigo, em que Porfíri Pietróvitch persegue Raskólnikov sem jamais acusá-lo formalmente, o que aumenta gradativamente a tensão que se estabelece em cada encontro de ambos é que, no filme de Bresson, o inspetor responsável pela 
investigação dos recorrentes roubos nas movimentadas estações de metrô e trem de Paris conhece a teoria do "homem superior" por meio de seu próprio criador; outros encontros se sucedem a esse até que, por fim, o inspetor acusa Michel, conscienciosamente, pelos roubos praticados. O jovem, assim como Raskólnikov, nega ser o responsável pelos crimes, mas isso pouco importa para aquele que veio visitá-lo. $O$ inspetor reage de modo indiferente, pois não tem dúvida alguma de que o criminoso que procura está diante de si. A situação da personagem de Bresson é ainda mais semelhante à de Raskólnikov se lembrarmos que o assassinato e o roubo não modificam a realidade em que vivem a personagem de Crime e castigo e Michel. Os crimes não podem alterar a "ordem" do mundo, que permanece exatamente o mesmo de antes.

Assim como no romance de Dostoiévski, no filme de Bresson encontramos um tipo de personagem que terá grande importância para o desfecho da obra e, consequentemente, para as vidas futuras dos protagonistas. Se em Crime e castigo Sônia é responsável por conduzir Raskólnikov rumo à redenção, acompanhando-o à delegacia e, posteriormente, à Sibéria, $O$ batedor de carteiras se encerra com a visita de Jeanne a Michel na prisão. Divididos pelas grades, que os afastam física e metaforicamente, por fim podemos enxergar alguma emoção expressa no rosto de Michel, cuja frieza e indiferença em relação a tudo e todos o caracterizavam até então. Ao concluir sua narrativa, Michel lamenta (mais uma vez em voiceover) os caminhos tortuosos percorridos até Jeanne, que para ele representa a materialização da esperança em uma nova vida. Para Michel, a visita de Jeanne é uma afirmação de que ela estará ao seu lado em qualquer circunstância. Nessa derradeira cena do filme de Bresson, não há qualquer diálogo verbal entre as personagens, o que não significa ausência de interação. O silêncio como recurso cinematográfico pode produzir sentidos que as palavras, talvez, não sejam capazes de alcançar com a mesma profundidade. Aqui, o diálogo é entre gestos e olhares; as personagens se tocam de modo apaixonado e, assim, se reconhecem no sofrimento de seu semelhante. Jeanne e Michel precisaram sofrer para, finalmente, serem capazes 
de encontrar a redenção nos braços um do outro. Tratar-se-ia, portanto, de um desfecho notadamente dostoievskiano, pois, como sabemos, não são poucas as obras do escritor russo que exploram a temática da salvação pelo sofrimento. Crime e castigo é, provavelmente, o exemplo mais conhecido.

Algumas características de ordem técnica presentes em $O$ batedor de carteiras demonstram que Bresson era um artista preocupado com o real (tal como o era Dostoiévski), mas que não ambicionava apresentar seus filmes como representações fiéis de uma realidade vivida. Para o diretor francês, a arte é assumidamente uma imitação do real, mas com este não se confunde:

Todo o cinema de Bresson está fundado numa lição e num paradoxo teatral: o falso, quando homogêneo, resulta verdadeiro. Para que o real se manifeste na tela, é preciso que nem a cena nem os atores tentem disfarçar o que são. Para Bresson, o real brota do artifício da representação assumido como tal e não das convenções do naturalismo. Por isso, preferia não trabalhar com atores, que são fingidores profissionais. Preferia a inexperiência dos iniciantes, os quais chamava de modelos."

Como percebe Bernardo Carvalho, o fingimento profissional, no entendimento de Bresson, deturpa o sentido do cinema enquanto manifestação artística. Nesse sentido, a arte deve, necessariamente, ser representação, pois é essa característica o que a aproxima da verdade, isto é, do mundo que chamamos de real. A opção por "modelos" ao invés de atores experientes é, ao lado do prólogo que introduz o filme de Bresson, uma maneira de dizer abertamente ao público que tudo o que se vê não é real. Paradoxal e conscientemente, o sentido que se produz é exatamente contrário: alcança-se o realismo através de uma aparente recusa a elementos que poderiam, em tese, servir como propulsores para seu ajustamento. Essa estratégia está presente em quase toda a cinematografia de Bresson. Especialmente, podemos lembrar aqui de outros dois filmes seus que, como $O$ batedor de carteiras, buscam inspiração nas obras de Dostoiévski: Uma mulher dócil (Une femme douce,

11 CARVALHO, 2007 
1969) e Quatro noites de um sonhador (Quatre nuits d'un rêveur, 1971). Ambos releem, respectivamente, Uma criatura dócil e Noites brancas. Ao lado de $O$ batedor de carteiras, esses filmes formam uma trilogia de obras que demonstram não apenas o valor que Bresson atribuía às obras de Dostoiévski, mas à própria literatura como expressão genuinamente artística. Afinal, recordemos que, para o diretor, o cinema é uma escrita com imagens e sons.

Finalmente, outro filme cuja influência de Dostoiévski, principalmente de suas Memórias do subsolo, se faz notar de maneira marcante é Taxi Driver (Taxi Driver - 1976), obra que colocou Martin Scorsese e Robert de Niro no hall dos grandes artistas do cinema. A respeito da influência que a novela do escritor russo exerceu nesse filme, Scorsese declarou em entrevista:

...one of the books I first read that was a strong impression on me, that I really wanted to do or to do versions of - or other versions of other works by this author - is Dostoevsky's Notes from the Underground. So this is the closest thing that I had come to. I didn't really think that literally. In other words, it took me a year or two after making the film to realize it all, I think, but it was just a visceral reaction to the power of the writing, really, and the character. ${ }^{12}$

A explicação do diretor acerca do filme, cujo roteiro é assinado por Paul Schrader, é interessante, sobretudo, por revelar que não houve, ao menos não de maneira intencional, desejo de realizar uma obra que pudesse ser vista como releitura da famosa novela de Dostoiévski. Scorsese confessa que somente após um ou dois anos se deu conta de que Taxi Driver estava fortemente impregnado da leitura que fizera de Memórias do subsolo. $O$ fato de essa influência, que parece muito clara para aqueles que conhecem a narrativa de Dostoiévski, não ter sido supostamente intencional apenas aumenta nosso interesse pelo filme.

12 ...um dos livros que li pela primeira vez que me causou uma forte impressão de que realmente queria fazer ou fazer versões de - ou outras versões de outras obras deste autor - são as Memórias do subsolo de Dostoiévski. Então essa é a coisa mais próxima que eu cheguei. Eu realmente não pensei isso literalmente. Em outras palavras, levei um ano ou dois depois de fazer o filme para perceber tudo, eu acho, mas foi apenas uma reação visceral ao poder da escrita, realmente, e do personagem (tradução nossa). SCORSESE, 2012. 
Travis e o "homem do subsolo" são exemplares perfeitos das contradições que constituíam os universos de que são oriundos. Solitários e ambíguos, esses indivíduos buscam, em ambientes corrompidos pelas mazelas sociais, algum tipo de reconhecimento que lhes faça existir e permita mostrar ao mundo que suas vidas têm algum sentido. Em suma, é essa tentativa de ser o que aproxima as personagens. Como sabemos, Dostoiévski aprofundaria essa investigação em Crime e castigo. Nesse romance, mais do que ser, Raskólnikov deseja realizar um ato heroico e, assim, contribuir de alguma forma para o "bem" da humanidade. $O$ assassinato da velha usurária e de sua irmã é um fracasso, ao passo que os crimes de Travis são recompensados ao fim da narrativa de Taxi driver. Após matar cafetões e mafiosos que exploravam sexualmente a jovem prostituta Íris, Travis entra em coma em virtude dos graves ferimentos. Quando sai, descobre que se tornou um verdadeiro herói para a sociedade; esta, finalmente, enxerga sua existência. Ignorado por Betsy, mulher por quem se apaixonara, Travis é procurado por ela quando volta a trabalhar nas ruas de Nova York. Eis seu maior triunfo. Antes completamente esquecido, agora Travis existe novamente diante dos olhos de alguém que outrora o desprezara por sua ignorância e aparente insignificância.

É interessante perceber como a ideia de Raskólnikov (a eliminação do mal) se faz presente no filme de Scorsese. Em Taxi driver, os contraditórios crimes cometidos por Travis são recompensados, e o sujeito é realmente visto como alguém que legou uma contribuição importante para o meio no qual estava inserido. É claro que o desfecho do filme é demasiado irônico, uma vez que escancara a identidade nociva de uma sociedade em que tudo que estiver à margem do aceitável deve ser sumariamente eliminado. Travis, como Raskólnikov, não teve intenção alguma de dar sua "contribuição" para a História. Sabemos quão egoístas são essas personagens; elas agem em prol de si mesmas. Na verdade, Travis planeja assassinar Charles Palantine, o senador e pré-candidato à presidência dos EUA, mas o acaso o impede de executar seu plano. Essa tentativa 
frustrada corrobora ainda mais a ideia de que a personagem não é movida por instintos nobres, mas unicamente por seus desejos e impulsos egocêntricos.

Ainda que o início da narrativa de Taxi Driver nos apresente Travis como um sujeito alienado, que nada entende de política ou cultura, é no mínimo curioso observar seu interesse pela escrita. Afinal, é através dessas anotações que "entramos" na história. Entre uma cena e outra, escutamos, em voiceover, a leitura de uma espécie de "diário", através do qual a personagem expõe seu cotidiano e suas impressões sobre o mundo (já observamos o mesmo recurso em $O$ batedor de carteiras). Aqui há, portanto, uma estreita relação entre Travis e o "homem do subsolo", pois ambos escrevem, em princípio, sem qualquer perspectiva de que seus textos sejam lidos com algum valor literário: "...eu escrevo unicamente para $\mathrm{mim}$, e declaro de uma vez por todas que, embora escreva como se me dirigisse a leitores, faço-o apenas por exibição, pois assim me é mais fácil escrever. Trata-se de forma vazia, e eu nunca hei de ter leitores. ${ }^{13}$ A escrita, nessas obras, é um subterfúgio particular para homens que podem expressar-se livremente e dizer 0 que pensam sem medo da censura moral a que poderiam estar sujeitos em sociedade. Além disso, mesmo se decidissem tornar públicos seus pensamentos, quem os escutaria? Quem estaria disposto a dar atenção às ideias de indivíduos que, por sua condição social, nada significam? Em Taxi driver, Travis é instigado a expor sua visão alegórica - para dizer o mínimo a respeito da sociedade. Quando o acaso (novamente!) coloca Charles Palantine como seu passageiro, o taxista finalmente se vê diante de alguém que escuta (ou finge escutar) o que ele tem a dizer. Paradoxalmente, algum tempo após esse encontro fortuito, Palantine se tornaria o alvo principal de Travis...

O desprezo pelo meio em que vivem e a misantropia certamente são características que as duas personagens centrais de Memórias do subsolo e Taxi driver compartilham entre si. Além disso, são sujeitos assumidamente doentes, que encontram na figura de jovens prostitutas, Liza e Iris, uma espécie de

13 DOSTOIÉVSKI, 2009b, p. 53 
fuga para as suas dores. Essas mulheres parecem representar, nas obras em questão, a imagem de tudo o que foi maculado pela sociedade, mas que ainda pode/deve ser "salvo". Se o "homem do subsolo" não logra sucesso nesse intento, Travis consegue devolver a jovem Iris a seus pais e, assim, reconstituir a ordem "natural" das coisas (de acordo com sua visão de mundo). Entretanto, ele o faz do modo mais violento possível, pois a linguagem da violência é a única que aprendeu no caótico cenário urbano que tem como habitat. Essa violência não impedirá que todos reconheçam em Travis um herói, o que possivelmente seria a maior diferença entre a personagem de Scorsese e a de Dostoiévski. Ora, o "homem do subsolo" se enxerga como um verdadeiro anti-herói: "um romance precisa de herói e, no caso, foram acumulados intencionalmente todos os traços de um anti-herói..."14 Mas, se nos permitirmos interpretar as atitudes de Travis de modo particular, não faremos coro com aqueles que o glorificam. Na verdade, ele também é, qual o narrador de Memórias do subsolo, um anti-herói, cujas ações não se pautam exclusivamente pelo desejo de auxiliar o próximo, senão pela necessidade irreprimível de vencer uma angústia que o atormenta e o impede de viver plenamente. Dessa forma, não há como pensar em Travis como herói, muito embora a narrativa seja construída em cima de ambiguidades para as quais não há, propositadamente, respostas definidas. Não sabemos, como expectadores, se torcemos para a felicidade ou castigo da personagem. Sua maneira de ver o mundo e seus atos parecem, por vezes, condenáveis, mas talvez se justifiquem pelo contexto alienante em que os indivíduos se acostumaram a viver. Quando Travis leva Betsy a um cinema pornográfico, parece que ele não se dá conta da vileza de sua atitude naquele momento. Todavia, é isso o que ele tem a oferecer. Sua alienação quase pueril transmite ao espectador um sentimento de compaixão e empatia; lamentamos as atitudes daquele homem que não sabe como agir diante de uma situação que exige dele o mínimo de etiqueta.

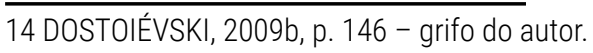


Nas palavras que serviram de epígrafe a este ensaio, Luiz Fernando Carvalho, diretor responsável por importantes adaptações cinematográficas de obras literárias no Brasil, explicita, de maneira metafórica, a estreita relação que o cinema manteve e mantém com a obra de Dostoiévski. Como vimos, esta tem sido constantemente adaptada por grandes diretores ao longo da jovem história da sétima arte. $O$ interesse pelos romances do escritor russo demonstra que os principais temas de que ele tratou continuam (e possivelmente continuarão) a instigar leitores e espectadores, que, quase sempre, não desejam apenas desfrutar de efêmeros momentos de prazer quando da leitura de uma obra, mas, sobretudo, conhecer melhor a si mesmos.

\section{Referências bibliográficas}

BAKHTIN, Mikhail. Problemas da poética de Dostoiévski. $5^{a}$ ed. Tradução de Paulo Bezerra. Rio de Janeiro: Forense Universitária, 2013.

BATEDOR de carteiras, O. Direção: Robert Bresson. França: Compagnie Cinématographique de France, 1959. 1 DVD (75 min.), son., p\&b., legendado.

BRESSON, Robert. Notas sobre o cinematógrafo. Tradução de Evaldo Mocarzel Riberolle. São Paulo: Iluminuras, 2014.

CARLOS, Cássio Starling. Crime e castigo: um filme baseado na obra de Dostoiévski. São Paulo: Folha de S. Paulo, 2013.

CARVALHO, Bernardo. A arte é o crime. Folha de São Paulo, São Paulo, 31 jul. 2007. Disponível em <https://www1.folha.uol.com. br/fsp/ilustrad/fq3107200727.htm>. Acesso em: 31 mai. 2020.

CARVALHO, Luiz Fernando. "Há um rebaixamento cultural, diz diretor Luiz Fernando Carvalho". Folha de São Paulo: São Paulo, 2017. Disponível em: <https://wwwl.folha.uol.com.br/ ilustrada/2017/01/1849754-ha-um-rebaixamento-cultural-diz-diretor-luiz-fernando-carvalho.shtml $>$. Acesso em 28 de jun. 2020. 
CRIME e castigo. Direção: Lev Kulidzhanov. União Soviética: Górki Film Studios, 1970. 1 DVD (211 min.), son., p\&b., legendado.

DOSTOIÉVSKI, Fiódor. Crime e castigo. Tradução de Paulo Bezerra. São Paulo: Editora 34, 2009a.

DOSTOIÉVSKI, Fiódor. Memórias do subsolo. Tradução de Boris Schnaiderman. São Paulo: Editora 34, 2009b.

GODARD, Jean-Luc. Godard on Godard. Tradução de Jean-Luc Godard. Nova York: Da Capo Press, 1972.

MITTERAND, Henri. 100 filmes: da literatura para o cinema. Tradução de Clóvis Marques. Rio de Janeiro: BestSeller, 2014. SCORSESE, Martin. "Martin Scorsese and Paul Schrader We're Looking at Taxi Driver". PopEntertainment.com : 2012. Disponível em:

<http://www.popentertainment.com/scorseseschrader.htm>. Acesso em: 28 jun. 2020.

TAXI driver. Direção: Martin Scorsese. EUA: Columbia Pictures, 1976. 1 DVD (114 min), son., color., legendado.

Recebido em: 04/08/2021 Aceito em: 09/11/2021 